\title{
Pergeseran Pola Konsumsi Leisure dan Non Leisure di Kota Semarang
}

\author{
Ola Ranti Dewi, Deky Aji Suseno² \\ Jurusan Ekonomi Pembangunan, Fakultas Ekonomi, Universitas Negeri Semarang \\ Permalink/DOI: https://doi.org/10.15294/efficient.v3i1.35968 \\ Received: July 2019 ; Accepted: October 2019 ; Published: January 2020
}

\begin{abstract}
Leisure consumption groups grew by $7.88 \%$ higher than the non-leisure group which grew by $6.27 \%$ in the year 2016. Data shows indications of a shift in consumption patterns. The purpose of this study was to analyze the shift in consumption patterns of Leisure and Non Leisure households in the city of Semarang, factors that influence the shift in consumption patterns. The research data was obtained from the BPS, and the questionnaire. The method used in this study is descriptive statistical analysis, Binary Logit Regression analysis using SPSS 25, and MPC analysis. The results of this study indicate that Leisure consumption growth in 2010-2017 is higher than the growth of non-leisure consumption which shows that there has been a shift in household consumption patterns in the city of Semarang. Shifting consumption patterns are influenced significantly by income and education level. Suggestions can be given to the government and society in general to be able to optimize the shift in consumption patterns, pay more attention to socio-economic factors of household income and education level, as well as focus on developing the economy in the field of leisure consumption in order to optimize consumption growth and total regional product.
\end{abstract}

Keywords: Household consumption expenditure, Consumption Pattern, Non Leisure, Leisure, Binary Logit, MPC

\begin{abstract}
Abstrak
Kelompok konsumsi leisure tumbuh sebesar 7,88\% lebih tinggi dari kelompok non leisure yang tumbuh sebesar 6,27\% pada tahun 2016. Data menunjukkan indikasi terjadinya pergeseran pola konsumsi. Tujuan penelitian ini untuk menganalisis pergeseran pola konsumsi Leisure dan Non Leisure rumah tangga kota Semarang, faktor yang mempengaruhi pergeseran pola konsumsi. Data penelitian ini diperoleh dari Badan Pusat Statistik, dan kuesioner. Metode yang digunakan dalam penelitian ini adalah analisis statistik deskriptif, analisis Regresi Logit Biner menggunakan SPSS 25, dan analisis MPC. Hasil penelitian ini menunjukkan bahwa pertumbuhan konsumsi Leisure pada tahun 2010-2017 lebih tinggi dibandingkan dengan pertumbuhan konsumsi non leisure yang menunjukkan bahwa telah terjadi pergeseran pola konsumsi rumah tangga di kota Semarang. Pergeseran pola konsumsi dipengaruhi secara signifikan oleh pendapatan dan tingkat pendidikan. Saran yang dapat diberikan kepada pemerintah dan masyarakat pada umumnya untuk dapat mengoptimalkan pergeseran pola konsumsi, lebih memperhatikan faktor sosial ekonomi pendapatan rumah tangga dan tingkat pendidikan, serta fokus dalam pengembangan perekonomian dibidang konsumsi leisure agar dapat mengoptimalkan pertumbuhan konsumsi dan PDRB.
\end{abstract}

Kata Kunci: Pengeluaran konsumsi rumah tangga, Pola Konsumsi, Non-Leisure, Leisure, Binary Logit, MPC

How to Cite: Dewi, O., \& Suseno, D. (2020). Pergeseran Pola Konsumsi Leisure dan Non Leisure di Kota Semarang. Efficient: Indonesian Journal of Development Economics, 3(1), 670-679. https://doi.org/10.15294/efficient.v3i1.35968

(C) 2019 Semarang State University. All rights reserved

\footnotetext{
Alamat Korespondensi :

Alamat: Gedung L2 Lantai 2 FE Unnes

Kampus Sekaran, Gunungpati, Semarang, 50229

E-mail : efficientjournal@gmail.com
} 


\section{PENDAHULUAN}

Manusia tidak akan berhenti melakukan konsumsi untuk memenuhi kebutuhan hidupnya. Konsumsi adalah kegiatan membeli barang dan jasa untuk memuaskan keinginan memiliki dan menggunankan barang tersebut (Sukirno, 2011). Pengeluaran konsumsi memberikan sumbangan yang sangat besar dalam perhitungan PDB. Pengeluaran konsumsi masyarakat memberikan kontribusi rata-rata sebesar 55\%-56\% dari total PDB nasional (BPS, 2017)

Pengeluaran konsumsi masyarakat dibedakan menjadi beberapa kategori berdasarkan jenis-jenis barang dan jasa. Pembagian kategori ini dilakukan untuk menghitung anggaran masing-masing rumah tangga. Konsumsi rumah tangga meliputi semua barang atau jasa yang di terima baik di produksi atau di konsumsi sendiri (Ahmed \& Mughal, 2018). Dalam perhitungan pengeluaran konsumsi masyarakat yang dilakukan oleh Badan Pusat Statistik (BPS) dibedakan menjadi tujuh komponen pengeluaran, yaitu: (i) Makanan, minuman selain restoran, (ii) Pakaian dan alas kaki, (iii) Perumahan, perkakas, dan perlengkapan penyelenggaraan rumah tangga, (iv) Kesehatan dan pendidikan, (v) Transportasi komunikasi, rekerasi dab budaya, (vi) Hotel dan restoran, (vii) Lainnya. (BPS, 2017). Besarnya proporsi dari pengeluaran konsumsi tiap komponen pengeluaran terhadap total pengeluaran disebut pola konsumsi. Pola konsumsi ialah berbagai informasi yang memberi gambaran mengenai macam dan jumlah bahan makanan yang dimakan setiap hari oleh satu orang yang merupakan ciri khas suatu kelompok masyarakat (Yulia, 2010).

Pertumbuhan konsumsi pada tahun 2017 tidak optimal, hal ini dibuktikan oleh data yang dikeluarkan oleh BPS, pertumbuhan konsumsi pada triwulan III 2017 hanya sebesar $4,93 \%$, tercatat sedikit lebih malambat dibandingkan triwulan II-2017 yang mencapai 4,95\%. Realisasi pertumbuhan konsumsi tersebut juga lebih rendah dibandingkan periode triwulan III-2016 yang tercatat 5,01\%. Perlambatan pertumbuhan konsumsi terlihat dari menurunnya pertumbuhan komponen makanan dan minuman, pakaian dan alas kaki, serta perumahan dan perlengakapan rumah tangga. Menurut kepala BPS Suhariyanto salah satu penyebab konsumsi rumah tangga tidak tumbuh optimal karena adanya pergeseran pola konsumsi masyarakat dari yang awalnya bersifat pembelian barang atau ritel (non-

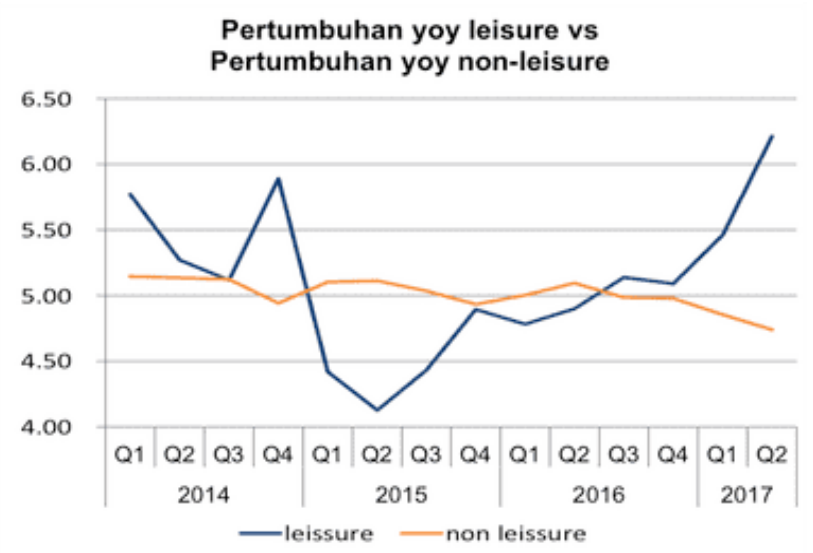

leisure) menjadi kegiatan waktu luang atau rekreasi (leisure) (Neraca.co.id, 2017).

Gambar 1. Pertumbuhan leisure dan non leisure (yoy)

Sumber: Badan Pusat Statistik (BPS), 2017

Leisure economy mulai popular di Indonesia dan dibicarakan para ahli ekonomi 
sejak pertumbuhan konsumsi untuk komponen seperti hotel, restoran, transportasi dan komunikasi kegiatan, rekreasi serta kebudayaan tumbuh cepat. Pergeseran pola konsumsi masyarakat terjadi karena masyarakat kini lebih tertarik menggunakan uangnya untuk kegiatan yang memberikan pengalaman seperti liburan, nongkrong, backpacker. Badan pusat statistik (BPS) mulai memperkenalkan pengelompokan konsumsi menjadi leisure dan non leisure, karena telah melihat gejala pergeseran pola konsumsi sejak tahun 2015. BPS menggolongkan komponen yang termasuk dalam leisure adalah hotel, restoran, rekreasi dan kegiatan kebudayaan. Kecenderungan pergesaran pola konsumsi pada gambar 1.1 pertumbuhan leisure dan pertumbuhan non leisure. BPS mencatat kelompok leisure pada kuartal IV 2016 tumbuh sekitar 5,1\%, dan pada kuartal II 2016 pertumbuhan tertinggi sebesar 6,3\%. Sedangkan untuk komponen non leisure pada kuartal IV 2015 tumbuh 5\%, sementara pada kuartal II 2017 4,3\%. Aktivitas leisure sangat diidentikkan dengan aktivitas konsumsi. Beberapa aktivitas konsumsi yang termasuk dalam kategori leisure meliputi kegiatan traveling, akomodasi di hotel, menikmati kuliner, film, dan konser musik, serta keinginan mengenal budaya yang beragam yang telah berkembang sebagai konsumsi gaya hidup masa kini (Ananda, 2018). Pertumbuhan konsumsi leisure ini karena masyarakat mulai menyadari bahwa menikmati hidup dapat dilakukan bersamaan dengan melakukan aktivitas ekonomi produktif. (Yuswohady, 2017). Jawa Tengah terdiri dari 35 kabupaten/kota, berdasarkan perbandingan PKRT di seluruh kebupaten/kota di Jawa
Tengah secara umum terdapat perbedaan antara wilayah yang berstatus kabupaten dengan daerah yang berstatus kota. Pada daerah kabupaten konsumsi makanan, minuman, selain restoran memberikan kontribusi mencapai 40\% dalam struktur penggunaan PKRT, sedangakan pada daerah kota yang sebesar 30\%. Secara umum, konsumsi makanan, minuman, selain restoran merupakan komponen utama dalam struktur penggunaan PKRT, namun suatu keunikan terjadi di Kota Semarang, yaitu pengeluaran konsumsi dengan proporsi terbesar berasal dari komponen transportasi, komunikasi, rekreasi dan budaya.

Kota Semarang sebagai ibukota provinsi Jawa Tengah telah menjadi pusat kegiatan ekonomi di Jawa Tengah termasuk perokonomian dan menjadi salah kota dengan volume perekonomian terbesar di Jawa. Struktur penggunaan pengeluaran konsumsi terbesar di Kota Semarang bukan dari makanan, minuman, selain restoran melainkan dari kelompok transportasi, komunikasi dan rekreasi. Berdasarkan data beberapa tahun kebelakang, pengeluaran konsumsi masyarakat kota Semarang menunjukkan indikasi adanya pergeseran pola konsumsi. Pola konsumsi masyarakat yang belum mapan biasanya didominasi oleh konsumsi kebutuhankebutuhan pokok (Anwar, 2010) Sejalan dengan kenaikan pendapatan per kapita, pola konsumsi berubah (Basri, 2017) yang dapat dilihat dari pertumbuhan konsumsi transportasi, dan telekomunikasi yang tumbuh sangat cepat (Dewhusrt, 2006). Penurunan pengeluaran konsumsi untuk makanan, namun diikuti dengan kenaikan pengeluaran untuk rekreasi (Yanrui $\mathrm{Wu}, 2007$ ) 
Berdasarkan pada penelitian terdahulu pergeseran pola konsumsi masyarakat dipengaruhi oleh faktor sosial ekonomi rumah tangga seperti pendapatan, jumlah anggota keluarga, usia anggota keluarga dan tingkat pendidikan (Esmawati, 2005). Semakin tinggi jumlah pendapatan maka pola konsumsi cenderung mengarah pada konsumsi non makanan, sebaliknya semakin rendah jumlah pendapatan maka pola konsumsi cenderung mengarah pada konsumsi makanan. Sehingga faktor pendapatan memiliki pengaruh terhadap kecenderungan pola konsumsi. (Hidayah, 2015). Penelitian yang dilakukan oleh (Adiana \& Karmini, 2016) menunjukkan bahwa pendapatan, jumlah anggota keluarga dan pendidikan berpengaruh terhadap pola konsumsi. Selain itu pola konsumsi juga dipngaruhi oleh keadaan kontraksi dan ekspansi ekonomi (Kamakura \& Du, 2012). Pergeseran pola konsumsi yang terjadi di Kota Semarang memerlukan perhatian khusus dari pemerintah. Pemerintah perlu membuat kebijakan baru atau menyesuaikan kebijakan yang ada untuk mendukung perubahan tatanan ekonomi yang terjadi akibat dari pergeseran pola konsumsi.

Tujuan yang akan dicapai dari penelitian ini adalah menjelaskan dan menganalisis Pergeseran pola konsumsi leisure dan non leisure rumah tangga, dan pengaruh pendapatan rumah tangga, jumlah anggota keluarga, usia anggota rumah tangga dan tingkat pendidikan rumah tangga terhadap pergeseran pola konsumsi di kota Semarang.

\section{METODE PENELITIAN}

Penelitian ini merupakan penelitian kuantitatif, yang menggunakan data primer dan sekunder. Data primer diperoleh dari 100 responden, pengeambilan sampel dilakukan dengan dua tahap yaitu tahap pertama menentukan cluster/area sampling, kemudian proportional random sampling. Data sekunder Badan Pusat Statistik kota Semarang serta beberapa studi pustaka relevan untuk melengkapi penelitian ini. Data sekunder yang diperoleh berupa data Pendapatan Domestik Regional Bruto (PDRB), dan pengeluaran masing-masing komponen konsumsi kota Semarang pada tahun 2010-2017. Variabel yang digunakan dalam penelitian ini adalah pendapatan rumah tangga, jumlah anggota rumah tangga, usia anggota rumah tangga dan tingkat pendidikan anggota rumah tangga. Jumlah anggota rumah tangga, adalah banyaknya orang yang tinggal dan makan bersama dalam suatu rumah tangga termasuk kepala rumah tangga. Tingkat pendidikan atau pendidikan tertinggi yang ditamatkan kepala rumah tangga. (Astuti, 2018) Teknik pengolahan dan analisis data yang digunaka adalah analisis statistik deskriptif, analisis indeks jawaban, analisis regresi logistik biner.

Uji Validitas dan Reabilitas dilakukan guna menguji sahih tidaknya setiap item pernyataan didalam mengukur variabel nya, sejauh mana suatu alat yang digunakan mampu untuk mengukur sesuatu yang diukur. Berdasarkan nilai koefisien korelasi masing masing pernyataan dalam kuesioner penelitian yang menunjukkan nilai di atas nilai R-tabel, maka keputusannya adalah pernyataan dalam kuesioner ini adalah valid sehingga dianggap sahih dan mampu untuk mengukur variabel dalam penelitian.

Reliabilitas adalah alat untuk mengukur suatu kuesioner yang merupakan alat pengukuran konstruk atau variabel. Suatu kuesioner dikatakan reliabel atau handal jika 
jawaban seseorang terhadap pertanyaan adalah konsisten atau stabil dari waktu ke waktu. Uji realiabilitas adalah tingkat kestabilan suatu alat pengukur dalam mengukur suatu gejala/kejadian. Berdasarkan pada nilai cronbach alpha, keputusan yang diambil adalah semua variabel reliabel sehingga kuesioner layak untuk digunakan.

Fungsi distribusi logistik dapat dinyatakan sebagai berikut (Widarjono, 2016) :

Perumusan model binari logit

$\mathrm{Pi}=\mathrm{F}(\mathrm{Zi})=\left(\beta \mathrm{o}+\beta_{1} \mathrm{Xi}\right)=1 / 1+\mathrm{e}^{-\mathrm{Zi}}=1 / 1+\mathrm{e}^{-}$ $\left(\beta_{0}+\beta_{1} X_{1}\right)$

Model regresi logistik biner dalam penelitian ini adalah sebagai berikut :

Ln $\frac{p}{1-p}=\beta_{o}+\beta_{1} X_{1}+\beta_{2} X_{2}+\beta_{2} X_{3}+\beta_{2} X_{4}+e$

Keterangan:

Ln $\frac{p}{1-p}=$ Terjadi/tidak terjadi pergeseran pola konsumsi

$\mathrm{X}_{1} \quad=$ Tingkat Pendapatan

$\mathrm{X}_{2} \quad=$ Jumlah Anggota Rumah Tangga

$\mathrm{X}_{3} \quad=$ Usia Anggota Rumah Tangga

$\mathrm{X}_{4} \quad=$ Tingkat Pendidikan

$\beta_{\mathrm{o}} \quad=$ Konstanta

$\beta_{1^{-}} \beta_{4}=$ Keofisien Regresi

e $\quad=$ error term

\section{HASIL DAN PEMBAHASAN}

\section{Analisis Indeks Jawaban}

Rata-rata indeks skor respon variabel pendapatan rumah tangga diperoleh 73,3. Berdasarkan kategori indeks skor three box metodh maka rata-rata tersebut berada pada tingkatan skor sedang. Kondisi ini menunjukkan bahwa secara umum persepsi responden terhadap peningkatan pendapatan maka akan mendorong pergeseran pola konsumsi dari non leisure menjadi leisure pada intensitas sedang.

Rata-rata indeks skor respon variabel pendapatan rumah tangga diperoleh 74,33. Berdasarkan kategori indeks skor three box metodh maka rata-rata tersebut berada pada tingkatan skor tinggi. Kondisi ini menunjukkan bahwa secara umum persepsi responden terhadap semakin banyak nya jumlah anggota keluarga maka akan mendorong pergeseran pola konsumsi dari non leisure menjadi leisure pada intensitas sedang.

Rata-rata indeks skor respon variabel pendapatan rumah tangga diperoleh 74,1. Berdasarkan kategori indeks skor three box metodh maka rata-rata tersebut berada pada tingkatan skor tinggi. Kondisi ini menunjukkan bahwa secara umum persepsi responden terhadap usia anggota rumah tangga maka akan mendorong pergeseran pola konsumsi dari non leisure menjadi leisure pada intensitas tinggi. Rata-rata indeks skor respon variabel pendapatan rumah tangga diperoleh 70,1. Berdasarkan kategori indeks skor three box metodh maka rata-rata tersebut berada pada tingkatan skor sedang. Kondisi ini menunjukkan bahwa secara umum persepsi responden terhadap tingkat pendidikan anggota rumah tangga maka akan mendorong pergeseran pola konsumsi dari non leisure menjadi leisure pada intensitas sedang

\section{Analisis Regresi Logistik Biner}

Uji simultan dilakukan untuk mengetahui signifikansi parameter terhadap model serentak (overall). Nilai $\quad-2 \quad$ Log 
likelihood 112,568 > chi square 9,48. Maka dapat diputuskan bahwa paling tidak ada variabel independen yang mempengaruhi variabel indenpenden. Uji koefisien determinasi menunjukkan bahwa variabel independen mampu menjelaskan variabel dependen sebesar $30 \%$.

Uji parsial yang dilakukan dengan uji wald, dikatakan berpengaruh jika nilai probabilitas Z tidak lebih besar dari alpha $(0,05)$. Variabel tingkat pendapatan signifikan dengan nilai $Z=15,881$ prob. o,ooo, jumlah anggota tidak signifikan dengan nilai $\mathrm{Z}=0,024$ prob. 0,959 usia anggota keluarga tidak signifikan dengan nilai $\mathrm{Z}=0,504$ prob. 0,504 dan tingkat pendidikan signifikan dengan nilai $\mathrm{Z}=3,969$ prob. 0,046 .

Uji kecocokan model dilakukan dengan melihat signifikan pada uji hosmer dan lameshow yang menunjukkan bahwa prob. Signifikansi o,637 lebih besar dari alpha. Sehingga keputusanya adalah model layak untuk digunakan.

Model regresi biner :

$\operatorname{Ln} \frac{p}{1-p}=-38,716+2,813 \mathrm{X}_{1}-0,42 \mathrm{X}_{2}-0,021 \mathrm{X}_{3}+$ $0,813 \mathrm{X}_{4}+\mathrm{e}$

Tabel 1. Koefisien Variabel Independen

\begin{tabular}{|c|c|c|c|}
\hline Variabel & Koefisien & Sig. & $\overline{\operatorname{Exp}(\mathrm{B})}$ \\
\hline Pendapatan (X1) & 2,813 & 0,000 & 16,666 \\
\hline $\begin{array}{l}\text { Jumlah Anggota } \\
\left(\mathrm{X}_{2}\right)\end{array}$ & 0,042 & 0,878 & 959 \\
\hline Usia Kepala $\left(\mathrm{X}_{3}\right)$ & $-0,021$ & 0,478 & ,980 \\
\hline $\begin{array}{l}\text { Tingkat } \\
\text { Pendidikan }\left(\mathrm{X}_{4}\right)\end{array}$ & 0,813 & 0,046 & 443 \\
\hline Konstanta & $-38,716$ & 0,000 & , ooo \\
\hline
\end{tabular}

Sumber: Output SPSS, 2018

\section{Odds Ratio}

Nilai odds ratio variabel pendapatan sebesar 16,666, angka ini bermakna kemungkinan setiap kenaikan pendapatan akan menaikkan kemungkinan terjadinya pergeseran pola konsumsi sebesar 16,666 kali. Nilai odds ratio variabel jumlah anggota rumah tangga sebesar 0,959, angka ini bermakna kemungkinan setiap kenaikan jumlah pendapatan akan menaikkan kemungkinan terjadinya pergeseran pola konsumsi sebesar 0,959 kali. Nilai odds ratio variabel usia sebesar o,980, angka ini bermakna kemungkinan setiap kenaikan usia anggota keluarga akan menaikkan kemungkinan terjadinya pergeseran pola konsumsi sebesar 0,980 kali. Nilai odds ratio variabel pendidikan anggota keluarga sebesar o,443, angka ini bermakna kemungkinan setiap kenaikan pendidikan anggota keluarga akan menaikkan kemungkinan terjadinya pergeseran pola konsumsi sebesar o,443 kali.

Leisure economy mulai menjadi pembahasan oleh pakar ekonomi ketika pada tahun 2017 banyak outlet ritel menutup usahanya dan terjadi tren penurunan bisnis ritel yang belum pernah terjadi sebelumnya di Indonesia (Kuntadi, 2018). Fenomena Leisure economy ditunjukan dengan terjadinya pergeseran pola konsumsi masyarakat Indonesia yang tidak lagi berselera membeli barang (material goods/goods based) namun lebih memilih mengahabiskan uang mereka untuk pengalama (experience). Fenemena pergeseran pola konsumsi dari Non leisure menjadi leisure yang terjadi di kota Semarang ditandai dengan tinggi permintaan masyarakat akan kebutuhan untuk waktu luang. Konsumsi masyarakat yang sebelumnya didominasi oleh kebutuhan untuk barang-barang yang bersifat 
goods-based (seperti sandang, pangan, papan), berubah menjadi experience-based consumption. Konsumsi leisure meliputi kegiatan travelling, akomodasi hotel, menikmati kuliner, film, menonton konser dan lain sebagainya. Konsumsi leisure ini mengakomodir sensasi kesenangan dan pengalaman yang sesuai dengan selera konsumen. Konsumsi leisure ini tidak hanya mengeluarkan uang untuk bersenang senang, namun juga dapat menghasilkan nilai tambah ekonomi.

Pergeseran pola konsumsi yang terjadi di Kota Semarang juga dibuktikan oleh pernyataan yang disampaikan oleh Walikota Semarang Hendrar Prihadi yang mengatakan bahwa saat ini kegiatan industri di kota Semarang sudah bergeser dari Manufacture Industry ke Tourism Industry. Pergeseran ini dibuktikan dengan meningkatnya jumlah hotel, retoran maupun cafe. Pada tahun 2011 jumlah hotel yang ada di Kota Semarang hanya 110, sampai pada tahun 2017 mencapai 301 hotel. Begitu pula dengan jumlah cafe dan restoran yang pada tahun 2011 hanya berjumlah 463 restoran kini sudah meningkat menjadi 825 restoran (Nashr, 2017).

Pergeseran pola konsumsi non leisure menjadi leisure menunjukkan bahwa sudah terjadi peningkatan kesejahteraan masyarakat di kota Semarang. Karena konsumen tentu akan terlebih dahulu memenuhi kebutuhan primer nya (non leisure) dan setelah kebutuhan tersebut sudah dipenuhi konsumen akan memenuhi kebutuhan untuk bersenangsenang. Peningkatan kesehateraan konsumen ini ditunjukan oleh peningkatan pendapatan perkapita masyarakat kota Semarang pada tahun 2010-2017. Peningkatan kesejahteraan masyarakat juga dibuktikan dengan pertumbuhan PDRB kota Semarang yang diikuti dengan semakin kecil yang proporsi konsumsi Non Leisure dan meningkatnya proporsi Leisure dalam struktur penggunaan PKRT di Kota Semarang. Hal ini sesuai dengan teori engel yang menyatakan tingkat kesejahteraan dikatakan membaik bila perbandingan pengeluaran untuk konsumsi makanan cenderung sedikit dan sebaliknya pengeluaran untuk konsumsi non makanan meningkat.

Hasil analisis ini dapat digunakan untuk menjawab pertanyaan permasalah pokok ekonomi modern yaitu what, how dan for whom. Berdasarkan pemaparan di atas dapat menjawab pertanyaan pertama yaitu what (barang apa yang perlu disediakan). Jenis barang atau jasa yang perlu dikembangkan adalah barang/jasa dalam penyediaan untuk memenuhi kebutuhan leisure masyarakat, diantaranya akomodasi transportasi, hotel, restoran, cafe, wisata. Selanjutnya untuk menjawab pertanyaan kedua yaitu how (bagaimana caranya). Dalam penyediaan barang leisure ini diperlukan kerjasama yang baik antara pemerintah, investor, pengusaha dan masyarakat pada umumnya. Pemerintah dituntut untuk memilih suatu sektor yang memiliki multiplier effect terhadap perekonomi (Suseno, 2017). Potensi di kota Semarang yang dapat dikembangkan adalah wisata religi, wisata bahari, wisata alam, wisata sejarah dan lain sebagainya. (Mustofa \& Haryati, 2018). Khususnya untuk pegembangan wisata khas Kota Semarang seperti Simpang Lima, Lawang Sewu, Goa Kreo, Sam Poo Khong, mall, dan lain sabagainya. Dan yang terakhir pertanyaan for whom (untuk siapa), 
penyediaan barang/jasa leisure untuk tentunya ditunjukan untuk masyarakat kota Semarang pada umumnya, terlebih lagi untuk masyarakat yang telah memiliki pendapatan di atas pendapatan perkapita kota Semarang sebesar 69,4 juta tiap tahun, atau sekitar 5 juta tiap bulan nya. Masyarakat yang memiliki pendapatan pada tingkatan seperti ini tentunya telah memiliki kesejahteraan yang baik, dan dapat memenuhi kebutuhan pokoknya, sehingga dapat memenuhi kebutuhan leisure (waktu luang) nya.

Variabel sosial ekonomi yang berpengaruh secara nyata adalah pendapatan rumah tangga dan tingkat pendidikan. Keadaan ini sesuai dengan hukum engel mengatakan bahwa rumah tangga yang memiliki pendapatan yang tinggi akan membelanjakan sebagaian kecil dari total pendapatan untuk pengeluaran kebutuhan pokok, sedangkan sebagian besar lebih digunakan untuk kebutuhan sekunder atau tersier. Pengeluaran untuk leisure ekonomi tidak termasuk dalam pengeluaran kebutuhan pokok. Melainkan untuk menikmati waktu luang dengan berwisata, jalan-jalan, makan direstoran dan lain sebagainya. Kemudia rumah tangga yang dengan tingkat pendidikan yang tinggi akan lebih banyak memiliki variasi dalam konsumsi nya, selain itu lebih memiliki perencanaan yang baik dalam konsumsi sehingga memilii anggaran untuk lebih banyak menikmati waktu luang.

\section{SIMPULAN}

Pola konsumsi rumah tangga Kota Semarang mulai menunjukkan pergeseran dari konsumsi Non leisure menjadi konsumsi Leisure. Variabel sosial ekonomi yang mempengaruhi pergeseran pola konsumsi adalah pendapatan rumah tangga dan tingkat pendidikan. Artinya bahwa para konsumsi Leisure memiliki potensi yang besar untuk dikembangkan sehingga dapat mengoptimalkan pertumbuhan konsumsi dan pertumbuhan perekonomian di Kota Semarang. Selain itu, pergeseran pola konsumsi rumah tangga menunjukkan bahwa terjadi peningkatan kesejahteraan rumah tangga Kota Semarang.

Fenomena pergeseran pola konsumsi yang terjadi di Kota Semarang yang merupakan kejadian yang belum pernah terjadi sebelumnya, sehingga pemerintah dan masyarakat pada umumnya perlu menyikapi dan mengoptimalkan pergeseran pola konsumsi non leisure dan leisure di Kota Semarang. Faktor sosial ekonomi seperti pendapatan dan tingkat pendidikan yang berpengaruh secara signifikan perlu lebih diperhatikan. Khusus nya tingkat pendidikan, pemerintah diharapkan dapat meningkatkan tingkat pendidikan masyarakat, sehingga dapat mendukung pergeseran pola konsumsi di Kota Semarang. Arah pengembangan perekonomian diharapkan berfokus pada sektor konsumsi leisure yang memiliki potensi besar untuk dikembangkan seperti tempat wisata, mall, kafe, restoran, hotel, akomodasi, atraksi wisata dan lain. Konsumsi Leisure mendapatkan perhatian khusus untuk memenuhi kebutuhan konsumsi leisure masyarakat. Sehingga dapat mengoptimalkan pertumbuhan konsumsi dan PDRB kota Semarang.

\section{DAFTAR PUSTAKA}

Adiana, P. P. E. \& Karmini, N. L., 2016. Pengaruh Pendapatan, Jumlah Anggota Keluarga dan Pendidikan Terhadap Pola Konsumsi Rumah Tangga Miskin di Kecamatan Gianyar. Jurnal Ekonomi Pembangunan, Volume 5, pp. 39-48. 
Ahmed, J. \& Mughal, M., 2018. They earn and send; we spend: consumption pattern of Pakistiani migrant household. International Journal of Sosial Economics, Volume 11.

Ananda, C. F., 2018. Bersiap Leisure Economy.

[Online]

Available at: http://feb.ub.ac.id/bersiapleisure-economy.html

[Diakses 02 Juni 2018].

Anwar, K., 2010. Analisis Determinan Pengeluaran Konsumsi Rumah Tangga Masyarakat Miskin di Kabupaten Aceh Utara. Jurnal Aplikasi Manajemen, Volume 8, pp. 1168-1177.

Astuti, E. W., 2018. Analisis Faktor-faktor yang mempengaruhi Kemiskinan Rumah Tangga (Kasus di kabupaten Semarang). JEJAK, pp. 162-185.

Basri, F., 2017. Pergeseran Pola Konsumsi. [Online]

Available

at:

https://faisalbasri.com/2017/08/14/perge seran-pola-konsumsi/

[Diakses 2018].

BPS, 2017. Produk Regional Domestik Bruto

Kota Semarang menurut Pengeluaran 2010-2016. Semaarang(Jawa Tengah): BPS Kota Semarang.

Dewhusrt, 2006. An Analysis of Consumer Expenditure in Queesland. Economics analysis and policy, Volume 20, pp. 169-188.

Esmawati, F., 2005. Analisis Konsumsi rumah tangga. Universitas Sebelas Maret, pp. 113-128.

Hidayah, M., 2015. Pola Konsumsi Rumah Tangga Pekerja Tambang Batu Kapur di
Desa Sidorejo Kecamatan Pojong Kabupaten Gunung Kidul. UNY.

Kamakura, W. \& Du, R. Y., 2012. How Economic Contraction and Expansion Affect Expenditure Pattern. Journal of Consumer Research, Volume 39, pp. 229-247.

Kuntadi, Y. A., 2018. Leisure Economy: Menikmati hidup sembari beraktivitas ekonomi produktif. [Online] Available at: https://www.watyutink.com/opini/Leisur e-Economy-Menikmati-hidup-sembariberaktivitas-ekonomi-produktif [Diakses 02 Juni 2018].

Mustofa, L. J. \& Haryati, T., 2018. Analisis Tipologi Potensi Pariwisata di Provinsi Jawa Tengah. JEJAK, Volume 7, pp. 187-193.

Nashr, J. A., 2017. Dari kota industri, Semarang bergeser menjadi kota wisata, Semarang: s.n.

Neraca.co.id, 2017. Ada Pergeseran Pola Konsumsi Masyrakat. [Online] Available at: http://www.neraca.co.id/article/92594/ad a-pergeseran-pola-konsumsimasyarakat-bps-pertumbuhan-kuartaliii-2017-hanya-506

Sukirno, S., 2011. Makroekonomi Teori Pengantar. Jakarta: Kharisma Putra Utama Offset.

Suseno, D. A., 2017. Multiplier Effect Sektor Basis Terhadap Perekonomian Daerah Provinsi Jawa Tengah. Jurnal Riset Ekonomi Pembangunan, pp. 113-126.

Widarjono, A., 2016. Ekonometrika Pengantar dan Aplikasinya Disertasi 
Panduan Eviews. Yogyakarta: UPP STIM YKPN.

Yanrui $\mathrm{Wu}$, 2007. Wealth and spending pattern in China. Internaional Journal of Social Economics, Volume 24, pp. 1007-1022.

Yulia, F., 2010. Pola konsumsi dan gaya hidup sebagai faktor resiko terjadinya hipertensi pada nelayan di kabupaten
Bintan kepulauan riau tahun 2009, Yogyakarta: UGM.

Yuswohady, 2017. Leisure Economy : Kekuatan Baru Konsumsi Generasi Milenial. [Online] Available at:

https://kawanpendi.com/2017/11/30/leisureeconomy-kekuatan-baru-konsumsi-generasimilenial/

$\begin{array}{llll}\text { [Diakses } & 02 & \text { Juni }\end{array}$

